\title{
Alteração Fisiológica da Cana-de-Açúcar pela Aplicação de GLYPHOSATE E SULFUMETURON-METHYL ${ }^{1}$
}

\author{
Physiological Alteration in Sugarcane Influenced by Glyphosate and Sulfumeturon-Methyl \\ Application
}

MESCHEDE, D.K. ${ }^{2}$, VELINI, E.D. ${ }^{3}$, CARBONARI, C.A. ${ }^{4}$ e SILVA, J.R.M. ${ }^{5}$

\begin{abstract}
RESUMO - O bloqueio parcial das rotas onde atuam os herbicidas, com uso de baixas doses, pode ter implicações importantes, como a alteração do balanço de processos metabólicos nas plantas. Assim, foi conduzido no ano agrícola 2006/2007 um experimento em cana-soca de segundo corte na Fazenda Jurema, pertencente ao grupo COSAN, município de Barra Bonita-SP, para verificar os efeitos do glyphosate e do sulfumeturon-methyl, em subdoses, no comportamento fisiológico da cana-de-açúcar pelos níveis de clorofila e carotenoides. Os tratamentos constituíram-se da aplicação de dois herbicidas: sulfumeturon-methyl (Curavial 360 e.a. $\mathrm{kg}^{-1}$ ) e glyphosate (Roundup 480 i.a. $\mathrm{kg}^{-1}$ ), isolados e em misturas, em diferentes doses, e um tratamento controle, sem a aplicação dos herbicidas. As doses utilizadas foram: glyphosate $200 \mathrm{~mL}$ p.c. ha- ${ }^{-1}$; glyphosate $400 \mathrm{~mL}$ p.c. ha ${ }^{-1}$; glyphosate 200 mL p.c. ha-1 +10 g p.c. ha ${ }^{-1}$ de sulfumeturon-methyl; glyphosate 150 mL p.c. ha ${ }^{-1}+$ $12 \mathrm{~g}$ p.c. ha ${ }^{-1}$ de sulfumeturon-methyl; e sulfumeturon-methyl $20 \mathrm{~g} \mathrm{p.c.} \mathrm{ha}{ }^{-1}$. O delineamento experimental utilizado foi o de blocos casualizados, com quatro repetições. As avaliações foram realizadas 15 e 30 dias após o plantio (DAP) e 30,60, 90, 120, 150 e 180 dias após a colheita (DAC). As folhas foram cortadas padronizando-se o mesmo peso e área foliar. Para determinação do conteúdo de clorofila e carotenoides, amostras de 0,2 g de tecido foliar fresco foram preparadas e os extratos filtrados, sendo efetuadas leituras em espectrofotômetro (663 e $645 \mathrm{~nm}$ para clorofilas $a$ e $b$, respectivamente). A aplicação de glyphosate e sulfumeturon-methyl nas maiores doses interferiu no conteúdo de carotenoides quando estes foram comparados com a testemunha. A maior dose de glyphosate diminuiu significativamente o conteúdo de clorofilas e carotenoides na cana-de-açúcar, porém esse resultado não se manteve quando a dose foi reduzida para $200 \mathrm{~mL}$ p.c. ha-1 ${ }^{-1}$ Os teores de clorofila foram inversamente proporcionais aos niveis Fe. A aplicação de sulfumeturonmethyl não interferiu nos teores de clorofila, no entanto os niveis de carotenoides se mostraram mais sensiveis e seus teores reduzidos. As alterações observadas nos niveis de clorofilas e carotenoides pela aplicação dos produtos podem afetar de maneira distinta o metabolismo da fotossintese pela absorção e/ou conversão de energia.
\end{abstract}

Palavras-chave: degradação, pigmento, metabolismo secundário.

\begin{abstract}
The partial blockage of the routes of action of herbicides, using low doses, may have important implications by altering the balance of the metabolic processes in plants. Thus, an experiment was conducted in cutting cane ratoon 2 at Cosan Group's Fazenda Jurema in Barra Bonita-SP, during the agricultural years 2006/2007, to verify the effects of glyphosate and sulfometuron methyl sub-doses on the physiological behavior of sugarcane based on the the levels of chlorophyll and carotenoids. The treatments consisted of applications of two herbicides: sulfometuron methyl $\left(480\right.$ a.i. $\left.\mathrm{kg}^{-1}\right)$ and glyphosate (360 a.e. $\left.\mathrm{kg}^{-1}\right)$ in different doses and mixtures (Roundup and Curavial, respectively), plus a control treatment, without herbicide application. The

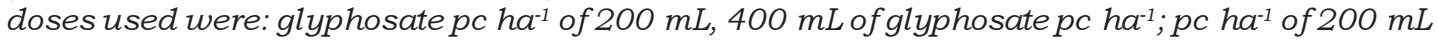

Recebido para publicação em 30.10.2010 e na forma revisada em 6.5.2011.

2 Pesquisadora, Dra ${ }^{\mathrm{a}}$, do Dep. de Produção Vegetal, FCA/UNESP, <meschede@fca.unesp.br>; ${ }^{3}$ Professor Adjunto do Dep. de Produção Vegetal, FCA/UNESP, <velini @fca.unesp.br>; ${ }^{4}$ Eng $^{\circ}$-Agro‥, Dr., do Dep. de Produção Vegetal, FCA/UNESP, <carbonari@fca.unesp.br>; ${ }^{5}$ Técnico do Laboratório de Matologia do Dep. de Produção Vegetal, FCA/UNESP.

Planta Daninha, Viçosa-MG, v. 29, n. 2, p. 413-419, 2011 
glyphosate $+10 \mathrm{~g}$ ofpcha-1 of sulfometuron methyl; pcha-1 of $150 \mathrm{~mL}$ glyphosate $+12 \mathrm{~g}$ of pc ha $\mathrm{a}^{-1}$ of sulfometuron methyl, sulfometuron methyl $p c$ ha ${ }^{1}$ of 20. The experiment was arranged in a randomized block design with four replications. The evaluations were carried out 15 and 30 days after planting (DAP) and 30, 60, 90, 120, 150 and 180 days after harvest (DAH). The leaves were cut using the same standardized weight and leaf area. To determine the content of chlorophyll and carotenoids, samples of $0.2 \mathrm{~g}$ of fresh leaf tissue were prepared and the extracts were filtered, and spectrophotometer readings were conducted 1663 and $645 \mathrm{~nm}$ for chlorophyll $a$ and $b$, respectively). The application of glyphosate and sulfumeturon methyl at larger doses were found to interfere in the carotenoid content, when compared with the control. The highest dose of glyphosate significantly reduced the content of chlorophyll and carotenoid in sugarcane, but this result was not maintained when the dose was reduced to $200 \mathrm{~mL}$. The contents of chlorophyll were inversely proportional to the levels of Fe. The application of sulfumeturon methyl did not affect the levels of chlorophyll; however, the carotenoid levels were more sensitive and were reduced. The changes observed in the chlorophyll and carotenoid levels caused by the application of the herbicides may distinctly alter the metabolism of photosynthesis by absorbtion and/or conversion of energy.

Keywords: pigments, secondary metabolism, degradation.

\section{INTRODUÇÃO}

Com o advento da crise mundial de energia, a cana-de-açúcar apresenta-se como principal fonte alternativa renovável, justificando a intensificação de estudos visando conhecer melhor o seu comportamento fisiológico. Essa cultura agrícola possibilita a produção de açúcar e de álcool, sendo importante fonte de energia renovável - aspecto relevante quanto à questão de sustentabilidade ambiental.

Dois dos principais pigmentos ligados à eficiência fotossintética e, consequentemente, ao crescimento e adaptação das plantas a diversos ambientes são a clorofila $a$ e os carotenoides (Force, 2003).

Nas plantas, a captação da luz se dá pelas folhas, e a transformação em energia ocorre nos cloroplastos, onde os pigmentos de clorofilas $a$ e $b$ absorvem a energia radiante necessária para a fotossíntese. Moléculas de clorofila encontram-se especificamente em complexos proteicos denominados fotossistemas, que são integrados nos tilacoides e cloroplasto. A maioria das moléculas de clorofila absorve luz e transmite a energia luminosa através de um fenômeno designado "transferência de energia por ressonância”. O fluxo de elétrons produzido pelos pigmentos de clorofila é usado para transportar íons $\mathrm{H}^{+}$ através das membranas dos tilacoides, provocando um potencial quimiosmótico, usado principalmente na produção de ATP. Os elétrons são eventualmente usados na redução de $\mathrm{NADP}^{+}$a NADPH (David \& Cox, 2004; Moraes et al., 2007).

A estrutura das clorofilas $a$ e $b$ é basicamente a mesma: compõem-se da porção porfirina, constituída de quatro anéis de pirrol ligados por pontes de carbono-hidrogênio. $\mathrm{O}$ íon metálico Mg está inserido no centro da porfirina (Romam, 2007; Tanaka \& Tanaka, 2007). O ácido $\delta$-minolevulínico, um aminoácido não proteico cuja via de biossíntese tem como precursor inicial o glutamato, é a molécula precursora da clorofila (Kannangara, 1991).

Os carotenoides também são pigmentos presentes em plantas. Um dos mais importantes é o betacaroteno, molécula precursora da vitamina A, cuja composição é exatamente a metade do carotenoide. O teor de carotenoides nos órgãos vegetais varia, sendo geralmente maior em folhas verdes (RodriguezAmaya et al., 2004). De modo direto ou indireto, a análise de clorofila e carotenoides é ferramenta para o diagnóstico nutricional e fotossintético.

Existe variação do teor de carotenoides em função de diferentes cultivares, dos estádios de maturação, das condições de clima ou localização geográfica, bem como da parte de planta utilizada e da técnica de produção agrícola. Por serem moléculas altamente insaturadas, os 
carotenoides são suscetíveis à isomerização e oxidação, que geralmente ocorre no processo de industrialização. Calor, luz e ácidos promovem a isomerização dos carotenoides trans, como são normalmente encontrados na natureza, para a forma cis, com ligeira perda de cor e atividade biológica. A oxidação, principal causa de degradação dos carotenoides, depende da disponibilidade de oxigênio, do tipo de carotenoide e de seu estado físico. A degradação é estimulada por luz, calor, metais, enzimas oxidativas e peróxidos, sendo inibida por antioxidantes.

Na literatura ainda há controvérsias em relação à interferência de herbicidas no conteúdo de clorofila e carotenoides. Alguns trabalhos mostram que o glyphosate pode diminuir os teores de clorofila por inibir a sintese do ácido aminolevulinato, precursor da clorofila (Siqueira et al., 1999). Já em outros não se verifica diferença significativa entre os tratamentos (Duarte et al., 2006; Meschede et al., 2007).

O que se sabe é que esses compostos, além de interferirem na sintese de clorofila, também podem afetar a formação de outros pigmentos, como xantofilas (Váradi et al., 2000) e carotenoides (Kim et al., 2004), causando interferência no fluxo de elétrons (Wakabayashi \& Böger, 2004) e redução na produção de ATP por inibição da atividade da ATP sintase no processo de fotofosforilação.

Como o uso de produtos químicos, maturadores ou herbicidas em doses reduzidas interfere de maneira e intensidade distinta no metabolismo da planta, objetivou-se neste trabalho verificar a influência do glyphosate e do sulfumeturon-methyl na fotossintese da análise dos niveis de clorofila $a, b$ e carotenoides, na pré-colheita e no desenvolvimento da cana após a colheita (rebrote).

\section{MATERIAL E MÉTODOS}

O experimento foi conduzido em cana-soca de segundo corte, variedade SP 803280, na Fazenda Jurema, no município de Barra Bonita, Estado de São Paulo (latitude de $22^{\circ}$ 38' 45"'S, longitude de $48^{\circ} 36^{\prime}$ ' $29^{\prime \prime} \mathrm{W}$ e altitude de $620 \mathrm{~m})$, pertencente ao grupo COSAN Unidade Barra.
O delineamento experimental adotado foi o de blocos ao acaso, com quatro repetições. Cada parcela foi constituída de $160 \mathrm{~m}^{2}$ (1,6 m entre plantas, em 10 linhas, e $10 \mathrm{~m}$ de comprimento). Como área útil foram consideradas as cinco linhas centrais. Os tratamentos constituíram-se da aplicação dos herbicidas sulfumeturon-methyl e glyphosate, que são encontrados comercialmente como Curavial (750 g de i.a. $\mathrm{kg}^{-1}$ ) e Roundup original (360 e.a. $\mathrm{kg}^{-1}$ ). As doses utilizadas foram: glyphosate $200 \mathrm{~mL}$ p.c. ha ${ }^{-1}$; glyphosate $400 \mathrm{~mL}$ p.c. ha ${ }^{-1}$; glyphosate $200 \mathrm{~mL}$ p.c. ha ${ }^{-1}+$ $10 \mathrm{~g}$ de sulfumeturon-methyl; glyphosate $150 \mathrm{~mL}$ p.c. ha ${ }^{-1}+12 \mathrm{~g}^{-1}$ de sulfumeturonmethyl; $20 \mathrm{~g} \mathrm{ha}^{-1}$ de sulfumeturon-methyl, sem a adição de adjuvantes; e a testemunha.

A aplicação dos produtos foi realizada em 11/10/2006, utilizando equipamento costal pressurizado $\left(\mathrm{CO}_{2}\right)$ com barra de $6 \mathrm{~m}$ de comprimento, em forma de $\mathrm{T}$, contendo seis pontas de pulverização AXI 11002, sendo a pressão de trabalho de 50 psi para a vazão de $100 \mathrm{~L} \mathrm{ha}{ }^{1}$. A umidade relativa do ar no momento da aplicação ficou em torno de $80 \%$, com velocidade do vento de $6 \mathrm{~m} \mathrm{~s}^{-1}$ e temperatura média de $25^{\circ} \mathrm{C}$.

As avaliações foram realizadas aos 15 e 30 dias após a aplicação dos herbicidas condição de pré-colheita. A soqueira da canade-açúcar foi avaliada aos 30, 60, 90, 120, 150 e 180 dias após a colheita.

Em cada época de avaliação, as amostras de folhas das plantas de cana-de-açúcar foram retiradas, conforme metodologia estabelecida para cada análise. Aos 15 e 30 dias após a aplicação dos produtos, em pré-colheita, as amostras de folhas foram coletadas em 15 plantas ao acaso por parcela, retirando-se folha do ponteiro (folha +1 ), parte mediana e inferior da planta. As folhas coletadas foram cortadas em círculos, por um equipamento que padronizou todas as amostras do mesmo tamanho; todas apresentavam a mesma área foliar e aproximadamente o mesmo peso.

Depois de padronizadas e homogeneizadas (misturaram-se as amostras das diferentes partes da planta, deixando uma amostra por planta), as amostras foram congeladas e, no final das avaliações, processadas.

Planta Daninha, Viçosa-MG, v. 29, n. 2, p. 413-419, 2011 
Na determinação do conteúdo de clorofila e carotenoides, amostras de 0,2 $\mathrm{g}$ de tecido foliar fresco foram trituradas com $\mathrm{N}$ líquido e depois colocadas em tubos com tampa contendo $10 \mathrm{~mL}$ de acetona $100 \%(\mathrm{v} / \mathrm{v})$. Os extratos foram filtrados, sendo as leituras realizadas em espectrofotômetro nos comprimentos de onda de 663 e $645 \mathrm{~nm}$ para clorofilas $a$ e $b$, respectivamente. As determinações dos niveis de clorofila ( $\mathrm{mg} \mathrm{gmf}^{-1}$ ) basearam-se nas equações relacionadas a seguir, segundo Whitham et al. (1971):

Clorofila $a=(11,24 \times$ A663 - 2,04 x A645),

Clorofila $b=(20,13 \times$ A645 - 4,19 x A663) e

Carotenoides $=(1000 \times$ A434 $-1,90$ Clorofila $a-$ 63.14 Clorofila b) / 214 ,

em que A é a absorvância no comprimento de onda indicado.

Os resultados foram submetidos à análise de variância pelo teste $\mathrm{F}$ a $5 \%$ de probabilidade e utilizou-se teste de $t$ a $5 \%$ de probabilidade para a comparação entre as médias. A probabilidade para comparação entre os tratamentos e a testemunha foi calculada: $1 /(100$ * $\left.2^{\mathrm{n}-2 \mathrm{x} \text { menor }}\right)$, em que $\mathrm{x}=$ valores acima da linha de tendência e $\mathrm{y}=$ valores abaixo da linha de tendência.

\section{RESULTADOS E DISCUSSÃO}

O conteúdo de clorofila $a$, $b$ e carotenoides variou significativamente em função dos tratamentos. A aplicação de glyphosate na maior dose (400 $\left.\mathrm{mL} \mathrm{ha}^{-1}\right)$ promoveu redução no conteúdo de clorofilas $a$ e $b$, quando em comparação com o da testemunha. Nos demais tratamentos não foram observadas diferenças significativas (Tabela 1).

A clorofila $a$ tem papel fundamental no processo de bioconversão de energia. De acordo com Moraes et al. (2007), as clorofilas $a$ e $b$ são interconvertidas no ciclo da clorofila e formam complexos de clorofila-proteina, que são importantes na regulação e na organização do fotossistema. Segundo Priori et al. (2003), há correlação positiva entre teor de clorofila e fotossintese líquida expressa em massa.

Os teores de carotenoides na folha foram mais sensiveis à aplicação dos herbicidas que os teores das clorofilas $a$ e $b$, sendo as maiores reduções observadas para o tratamento com a mistura de glyphosate e sulfumeturon-methyl (400 $\mathrm{mL} \mathrm{ha}^{-1}$ e $20 \mathrm{~g} \mathrm{ha}^{-1}$, respectivamente). Doses reduzidas dos produtos não interferiram na característica avaliada.

A rota de sintese de carotenoides em plantas ocorre a partir do ácido mevalônico e fornece os componentes necessários à produção de vários reguladores do crescimento vegetal, destacando-se citocininas, giberelinas e ácido abscísico. As transformações de geranil-pirofosfato, farnesil-pirofosfato, geranilgeranil-pirofosfato (com participação das enzimas prenil-transferase e farnesil tranferase) e, posteriormente, a transformação do fitoeno em fitoflueno correspondem a passos metabólicos, os quais alteram

Tabela 1 - Estimativa dos teores de clorofilas $a$ e $b$ e carotenoides em cana-de-açúcar, variedade SP 803280, aos 30 dias após a aplicação dos maturadores. Barra Bonita-SP, 2006

\begin{tabular}{|c|c|c|c|}
\hline \multirow{2}{*}{ Tratamento } & Clorofila $a$ & Clorofila $b$ & Caratenoides \\
\hline & \multicolumn{3}{|c|}{$\left(\mathrm{mg} \mathrm{dm}^{-3}\right)$} \\
\hline 1. Glyphosate $200 \mathrm{~mL} \mathrm{ha}^{-1}$ & 11,49 & 2,76 & 2,74 \\
\hline 2. Glyphosate $400 \mathrm{~mL} \mathrm{ha}^{-1}$ & 8,28 & 1,96 & 1,91 \\
\hline 3. Glyphosate $200 \mathrm{~mL}+$ sulfuron-methyl $10 \mathrm{~g} \mathrm{ha}^{-1}$ & 12,73 & 2,91 & 3,18 \\
\hline 4. Glyphosate $150 \mathrm{~mL}+$ sulfuron-methyl $12 \mathrm{~g} \mathrm{ha}^{-1}$ & 14,48 & 3,36 & 3,65 \\
\hline 5. Sulfumeturon-methyl $20 \mathrm{~g} \mathrm{ha}^{-1}$ & 13,05 & 3,06 & 2,83 \\
\hline 6. Testemunha & 14,12 & 5,01 & 3,72 \\
\hline F tratamento & $4,36^{*}$ & $3,97 *$ & $5,03 *$ \\
\hline F bloco & $0,55^{\mathrm{ns}}$ & $0,34^{\mathrm{ns}}$ & $1,76^{\mathrm{ns}}$ \\
\hline CV $(\%)$ & 20,43 & 24,52 & 15,27 \\
\hline DMS & 4,19 & 1,21 & 1,07 \\
\hline
\end{tabular}

* Significativo pelo teste $\mathrm{T}$ a $5 \%$, ${ }^{\mathrm{ns}}$ não significativo. 
os teores de carotenoides na planta. No entanto, na passagem do fitoeno para fitoflueno são necessários elétrons cedidos pela plastoquinona, que são produzidos na rota do ácido chiquímico.

Durante o crescimento da cana, os teores de clorofilas e os carotenoides tiveram comportamentos semelhantes diante da aplicação dos tratamentos. Contudo, os carotenoides mostraram-se mais sensiveis e tiveram seus teores reduzidos pela aplicação do glyphosate (400 mL p.c. ha $\mathrm{h}^{-1}$, como ocorreu com os teores de clorofila, mas também pela aplicação de sulfumeturon-methyl 20 g p.c. ha ${ }^{-1}$, como já tinha sido observado em pré-colheita.

Os resultados da comparação da aplicação do glyphosate isolado em relação à testemunha mostram claramente o efeito deletério no teor de clorofila quando o glyphosate é aplicado na maior dose. Contudo, esse efeito não se mantém quando se reduz a dose para $200 \mathrm{~mL} \mathrm{ha}^{-1}$ (Figura 1).

Segundo Marschner (1995), a biossintese da clorofila necessita de duas enzimas-chave:
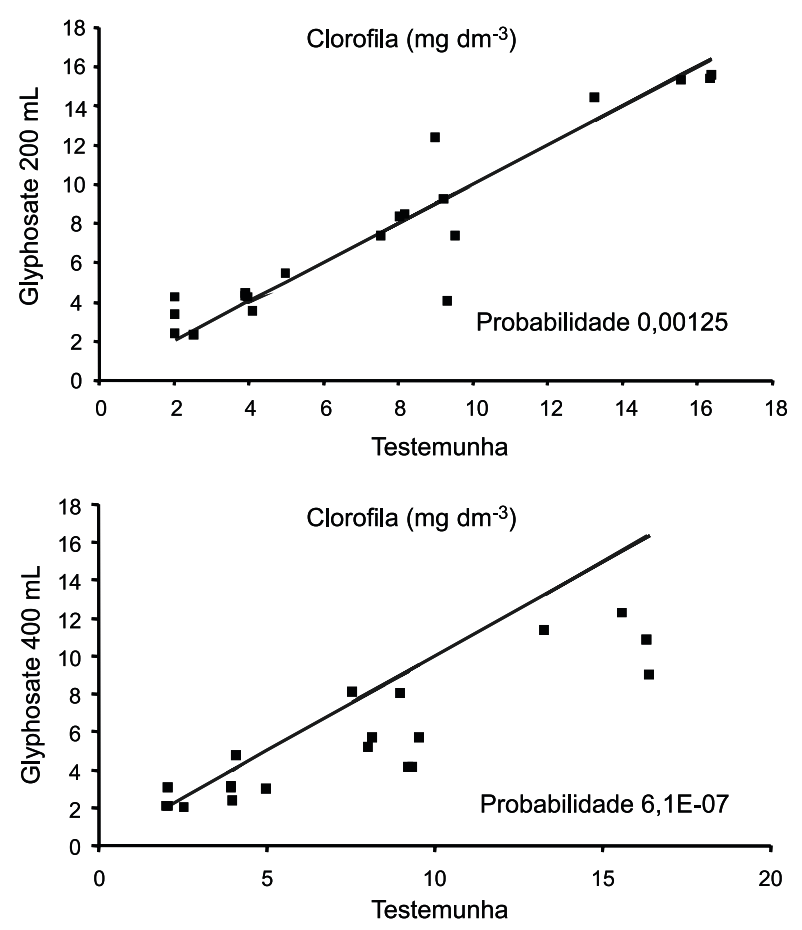

Figura 1 - Teores de clorofila em cana-de-açúcar que recebeu aplicação de glyphosate nas doses de 400 e $200 \mathrm{~mL}$ em relação à testemunha, em pré-colheita. Barra Bonita-SP, 2007. a catalase e a peroxidase, que são muito sensiveis à deficiência de ferro. Nilsson (1985), observando o efeito de metais como o $\mathrm{Fe}^{3+}$ e o $\mathrm{Mn}^{2+}$ na redução da fitotoxicidade do glyphosate, constatou que esse fenômeno seria devido à menor absorção do produto pela ação desses metais ou pela formação de complexos estáveis, nos quais o glyphosate permaneceria inativo mesmo após a entrada na planta.

Analisando o comportamento da clorofila e a aplicação do glyphosate, e comparando com os niveis de $\mathrm{Fe}$, constatou-se correlação negativa entre a concentração de Fe e clorofilas (Figura 2). Segundo Benincasa (1988), apesar de não se poder quantificar a importância da fotossintese e dos nutrientes separadamente, há estreita relação entre os dois, de tal forma que a deficiência em um prejudica o outro direta ou indiretamente.

$\mathrm{Na}$ análise de carotenoides, assim como na avaliação de pré-colheita, os respectivos teores de carotenoides foram influenciados pela aplicação de glyphosate e sulfumeturonmethyl, na dose comercial. Quando a dose de glyphosate foi reduzida para $200 \mathrm{~mL}$ p.c. os efeitos negativos foram menores, e os teores de carotenoides apresentaram-se bem próximos aos observados na testemunha (Figura 3).

Por serem moléculas altamente insaturadas, os carotenoides são suscetiveis a isomerização e oxidação, que geralmente ocorre no metabolismo da planta em função da

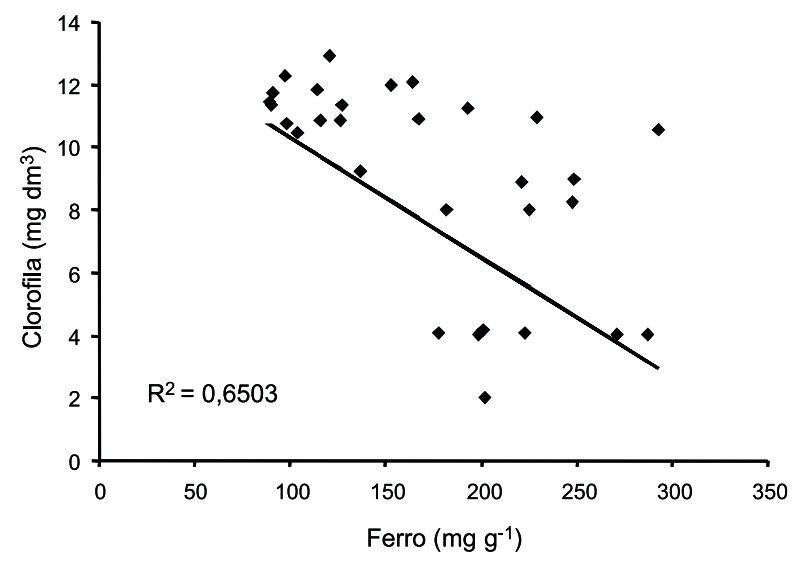

Figura 2 - Relação entre os teores de clorofila e Fe em cana após a aplicação de glyphosate na dose de $400 \mathrm{~mL}$ de p.c ha-1. Barra Bonita-SP, 2007. 

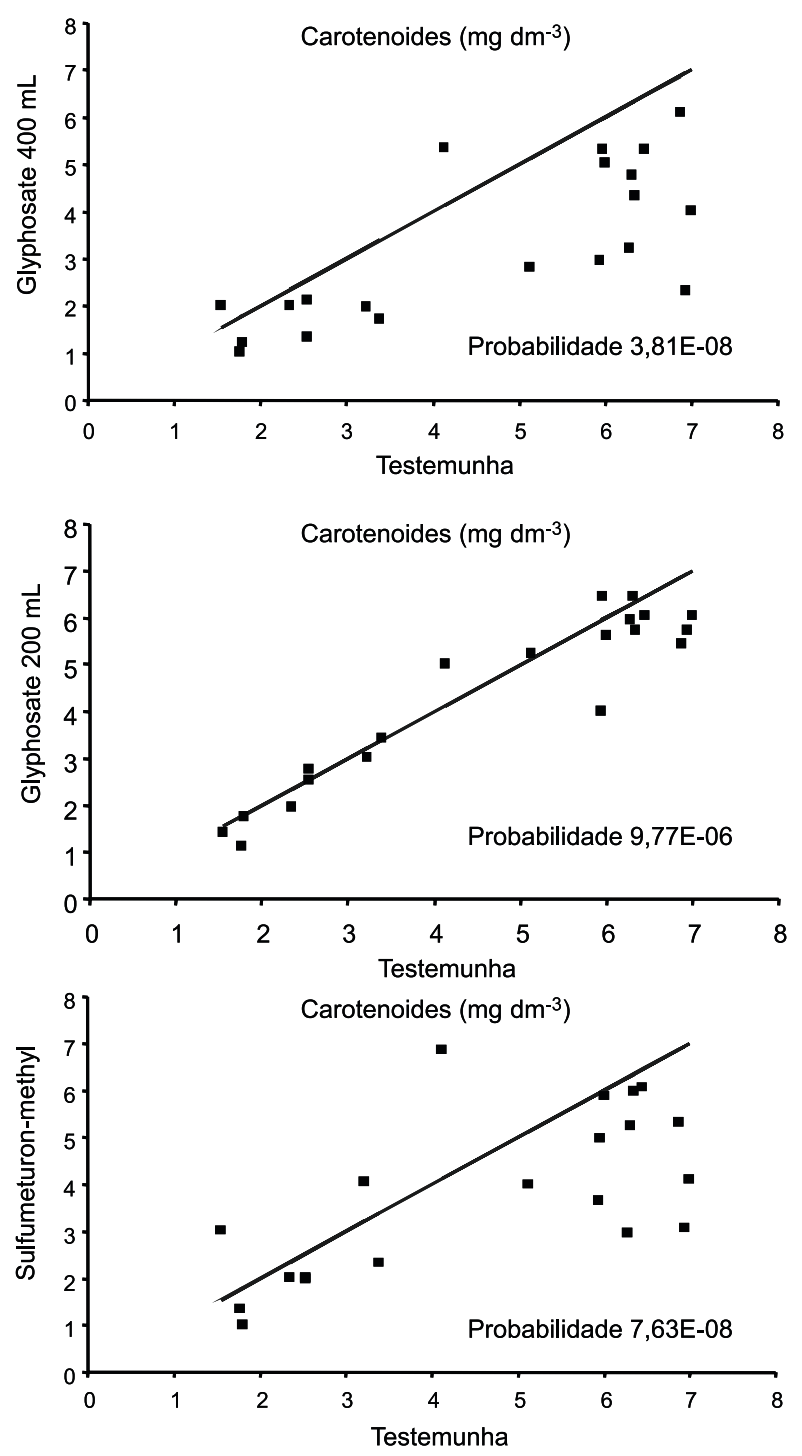

Figura 3 - Teores de carotenoides observados na cana-de-açúcar após a aplicação de glyphosate $400 \mathrm{~mL}$ p.c. ha-1 e sulfumeturon-methyl. Barra Bonita-SP, 2007.

aplicação de herbicidas. O calor, a luz e o pH promovem a isomerização dos carotenoides trans, como são normalmente encontrados na natureza, para a forma cis, com ligeira perda de cor e atividade biológica. A oxidação, principal causa de degradação dos carotenoides, depende da disponibilidade de oxigênio, do tipo de carotenoide e de seu estado físico. É estimulada pela luz, calor, metais, enzimas oxidativas e peróxidos e inibida por antioxidantes.

Pelos resultados analisados, é possivel observar que a aplicação de glyphosate e sulfumeturon-methyl nas maiores doses testadas pode interferir na fotossintese, por diminuir os teores de clorofila e carotenoides da planta.

As análises de clorofila, principalmente de carotenoides, mostraram-se um bom indicador para avaliar efeitos de fitotoxicidade desses produtos e sua possivel interferência no processo fotossintético da cana-de-açúcar.

\section{LITERATURA CITADA}

BENINCASA M. M. P. Análise de crescimento. Jaboticabal: FUNEP, 1988. $42 \mathrm{p}$

DAVID, N. L.; COX, M., Lehninger principles of biochemistry. 4. ed.. W.H.Freeman, 2004. 1100 p.

DONATO, V. M. T. S. et al. Atividade enzimática em variedades de cana-de-açúcar cultivadas in vitro sob diferentes níveis de nitrogênio. Pesq. Agropec. Bras., v. 39, n. 11, p. 1087-1093, 2004

DUARTE, N.F. Seletividade de herbicidas sobre Myracrodruon urundeuva (aroeira). Planta Daninha, v. 24, n. 2, p. 329-337, 2006.

FORCE, L.; CRITCHLEY, C., VAN RENSEN, J. J. S. New fluorescence parameters for monitoring photosynthesis in plants. Photosynthesis Research, n. 78, p. 17-33, 2003.

KANNANGARA, C. G. Biochemistry and molecular biology of chlorophyll synthesis. In: BOGORAD, L.; VASIL, I.K. (Ed.). Cell culture and somatic cell genetics of plants. San Diego: Academic Press, 1991. v. 7B. p. 301-322.

KIM, J. S. et al. Death mechanisms caused by carotenoid biosynthesis inhibitors in green and in undeveloped platissues. Pest. Bioch. Physiol., v. 78, n. 3, p. 127-139, 2004.

MALAVOLTA, E. et al. Avaliação do estado nutricional das plantas: princípios e aplicações. 2.ed. Piracicaba: Potafos, 1997. 319 p.

MESCHEDE, D. K.; VELINI, E. D.; CARBONARI, C. A. Teores de clorofilas e carotenóides na cana-de-açúcar submetida à aplicação de maturadores. In: SIMPÓSIO INTERNACIONAL SOBRE GLYPHOSATE, 1., 2007, Botucatu. Anais... Botucatu: FEPAF, 2007. p. 296-298.

MORAIS, R. R. et al. Chloroplastid pigment contents and chlorophyll $a$ fluorescence in amazonian tropical three species. R. Árvore, v. 31, n. 5, p. 959-966, 2007. 
PRIORI, L.D.; EAMUS,D.; BOWNAN, D.M.J.S. Leaf attributes in the seasonally dry tropics: a comparison of four habitats in northen Austrian. Functional ecology, v. 1, n. 17, p. 504-515, 2003.

RODRIGUEZ-AMAYA, D; KIMURA, M. HARVESTPLUS Handbook for carotenóides analysis. Washington, DC and Cali: IFPRI and CIAT, 2004. 58 p. (HarvestPlus Technical Monograph, 2)

ROMAM, E. S. Como funcionam os herbicidas - Da biologia á aplicação. Passo Fundo, RS: Berthier, 2007. $159 \mathrm{p}$.
TANAKA, R.; TANAKA, A. Tetrapyrrole bosynthesis in higher plants. Annual Review of plant Biology, v. 58, p. 321-346, 2007.

WAKABAYASHI, K.; BÖGER, P. Phytotoxic sites of action for molecular design of modern herbicides (Part 1): the photosynthetic electron transport system. Weed Biol. Manag., v. 4, n. 1, p. 8-18, 2004.

WHITHAM, F.H.; BLAYDES, D.F.; DEVLIN, R.M. Experiment in plant physiology. New York: D. Van Nostrand Company, 1971. p. 55-58. 